\section{Pain: an increasingly common cause of discharge from military service}

\author{
Louise G Holden
}

This edition of the Journal of the Royal Army Medical Corps presents two articles dealing with pain. In their review of phantom limb pain, Le Feuvre and Aldington $^{1}$ demonstrate the impact that pain can have on recovery and how a multi-disciplinary approach is essential for optimising patient outcome. In particular, they note 'the importance of attending to the patient's psychosocial needs and concerns'. This is not unique to phantom limb pain but is common across the management of all pain. ${ }^{2}$

In another paper on the prevalence of pain in military amputees, Aldington and colleagues found that $49 \%$ suffered phantom limb pain; ${ }^{3}$ two-thirds also had residual limb pain. Significant amputation nearly always results in discharge from military service in the UK Armed Forces, ${ }^{4}$ with 80 of the service personnel who have sustained amputations in Afghanistan already having been medically discharged. This is predominantly because of the functional limitations of the amputation, but pain can be a contributory factor to the degree of limitation.

The contribution of pain as a factor affecting functional capacity for military service is frequently noted by Medical Boards assessing patients for their fitness for continuing service. Anecdotally, military occupational physicians perceive that pain is a frequent cause of a Medical Board declaring a patient as unfit for military service.

To ascertain the true picture, data from Defence Statistics were examined. The crude rate of medical discharge (per 1000 strength of UK Regular Army personnel) with a principal condition of pain or where pain was a contributory (but not principal) condition in 2005-2013 is illustrated (Figure 1). Table 1 provides data for all three Services; the increase in medical discharges with a principal cause of pain between 2005/2006 and 2012/ 2013 is statistically significant across all

Correspondence to Col Louise G Holden, Medical Strategy and Policy, HQ Surgeon General, Coltman House, DMS WHITTINGTON, Whittington Barracks, Lichfield, Staffordshire WS14 9PY, UK; SGACDSStratPol-MedPolDptyHd@mod.uk, Louise.holden350@mod,uk three Services (two-sample Z tests of proportions; 95\% confidence level).

However, the overall rate of medical discharges has increased over those years too, so it is important that pain is considered in the context of all the other causes of medical discharge (Table 2).

Thus, large proportions of Service medical discharges have been attributable to pain and there has been a significant increase in numbers since 2005-2006. For the Army, the numbers have increased but the proportion of overall discharges decreased; both the RAF and the RN had increases in the proportion of pain-related

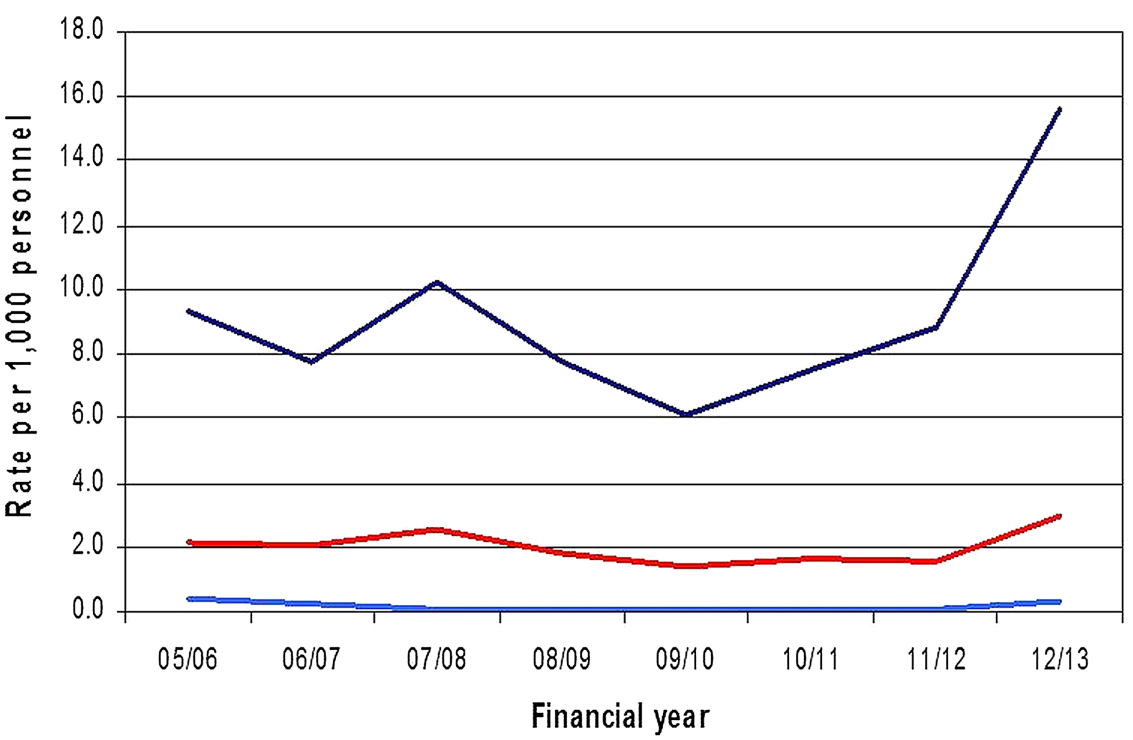

All Army medical discharges _Pain as Principal cause _Pain as a contributory cause

Figure 1 Regular Army medical discharges and relationship to pain (2005-2013) per 1000 personnel.

Table 1 UK Regular Armed Forces medical discharges in 2005/2006 and 2012/2013 caused, or contributed to, by pain (crude rates per 1000 serving personnel and percentage differences over time)

\begin{tabular}{|c|c|c|c|c|c|c|}
\hline & \multicolumn{3}{|c|}{ Pain as principal cause } & \multicolumn{3}{|c|}{$\begin{array}{l}\text { Pain as a contributory (but not principal) } \\
\text { cause }\end{array}$} \\
\hline & $2005 / 2006$ & $2012 / 2013$ & $\%$ difference & $2005 / 2006$ & $2012 / 2013$ & $\%$ difference \\
\hline Naval Service & 1.9 & 2.7 & +42 & 0.3 & 0.3 & +22 \\
\hline Army & 2.2 & 3.0 & +38 & 0.4 & 0.3 & -16 \\
\hline RAF & 0.3 & 2.0 & +531 & 0.2 & 0.3 & -72 \\
\hline
\end{tabular}

Naval service includes Royal Navy and Royal Marines. ick thus preparing Service personnel better for transition to civilian life. The earlier falls in discharge rates from 2008 to 2010 are likely to be due to a combination of causes, including difficulties in recruiting and the retention, rather than discharge, of personnel injured on operations.

The cause for the changes in painrelated discharge rates cannot be derived these data alone. However, the increase and the high proportion of discharges where pain is the principal

discharges, with that of the RAF reaching significance.

The reasons for the increase in overall down to more rigorous application of medical standards and personnel policies by both medical staff and the chain of mand. There has also been significan 
Table 2 UK Regular Armed Forces Medical discharges with a cause of pain as a proportion of all 'cause-coded' medical discharges in 2005/2006 and 2012/2013

\begin{tabular}{|c|c|c|c|c|c|c|}
\hline & \multicolumn{3}{|c|}{ Pain as principal cause } & \multicolumn{3}{|c|}{ Pain as a contributory (but not principal) cause } \\
\hline & $2005 / 2006(\%)$ & $2012 / 2013(\%)$ & $\%$ difference & $2005 / 2006(\%)$ & 2012/2013 (\%) & $\%$ difference \\
\hline Naval Service & 19.7 & 22.1 & +2.5 & 2.9 & 2.8 & -0.1 \\
\hline Army & 24.2 & 19.4 & $-4.8^{*}$ & 4.2 & 2.1 & -2.1 \\
\hline RAF & 11.7 & 39.3 & $+27.6^{*}$ & 6.6 & 1.0 & -5.6 \\
\hline
\end{tabular}

condition leading to discharge illustrate the need for access to good quality pain management in order to maximise recovery and functional outcome. This will allow some personnel to continue to serve in the Armed Forces, thus reducing the costs to the Service and the individual from loss of service employment and, for those who are still medically discharged, maximise their capacity for future employment outside the military. It should enhance their quality of life and potentially reduce future societal costs.

The principles of treatment proposed for pain management in amputees by Le Feuvre and Aldington ${ }^{1}$ are also likely to be suitable for military personnel with pain from other conditions and are used for the treatment of all musculo-skeletal conditions at the Defence Medical Rehabilitation Centre.

Medical Boards have an important role in ensuring that patients have had access to such services by assessing if a patient's pain management has been optimally addressed.
Primary care staff must also be cognisant of the impact of pain on the ability to sustain employment in the Armed Forces and ensure that their patients are appropriately managed and referred. Early consultation with Regional Occupational Health Specialists is vital to avoid prolonged sickness absence with its associated low rates of return to duty; likewise, primary care and occupational health staff must encourage the military chain of command to take full advantage of the extensive recovery capabilities available for those personnel who are unfit for normal military duties. Having an active programme of appropriately tailored training, work placements and adventurous training and sport will support and complement the medical treatment of pain, particularly addressing bio-psychosocial needs.

Those planning and commissioning health services for Armed Forces personnel need to be aware of the importance of pain management in maximising the capacity of Armed Forces personnel for work.
Contributors This work is solely my own with statistics and analysis supplied by Defence Statistics.

Competing interests None.

Provenance and peer review Commissioned; internally peer reviewed.

To cite Holden LG. J R Army Med Corps 2014:160:2-3.

Accepted 24 January 2014

J R Army Med Corps 2014;160:2-3.

doi:10.1136/jramc-2013-000229

\section{REFERENCES}

1 Le Feuvre $P$, Aldington $D$. Know pain know gain: proposing a treatment approach for phantom limb pain. J R Army Med Corps 2014;160:4-8.

2 Roditi E, Robinson ME. The role of psychological interventions in the management of patients with chronic pain. Psychol Res Behav Manag 2011:4 41-9.

3 Aldington D, Small C, Edwards D, et al. A survey of post-amputation pains in serving military personnel. JR Army Med Corps 2014;160:26-9.

4 UK Defence Statistics. http://www.dasa.mod.uk/ publications/health/operational-casualties/amputations/ 2013-09-30/30-september-2013.pdf (accessed 2 Jan 2014) 